\title{
Comparing Canopy Hyperspectral Reflectance Properties of Palmer amaranth to Okra and Super-Okra Leaf Cotton
}

\author{
Reginald S. Fletcher ${ }^{1}$, Rickie B. Turley ${ }^{2}$ \\ ${ }^{1}$ Crop Production Systems Research Unit, Agricultural Research Service, United States Department of Agriculture, \\ Stoneville, USA \\ ${ }^{2}$ Crop Genetics Research Unit, Agricultural Research Service, United States Department of Agriculture, Stoneville, USA \\ Email: reginald.fletcher@ars.usda.gov
}

How to cite this paper: Fletcher, R.S. and Turley, R.B. (2018) Comparing Canopy Hyperspectral Reflectance Properties of Palmer amaranth to Okra and Super-Okra Leaf Cotton. American Journal of Plant Sciences, 9, 2708-2718.

https://doi.org/10.4236/ajps.2018.913197

Received: September 24, 2018

Accepted: December 22, 2018

Published: December 25, 2018

Copyright $\odot 2018$ by authors and Scientific Research Publishing Inc. This work is licensed under the Creative Commons Attribution International License (CC BY 4.0).

http://creativecommons.org/licenses/by/4.0/

\begin{abstract}
Palmer amaranth (Amaranthus palmeri S. Wats.) is a major weed problem of cotton (Gossypium hirsutum L.) production systems in the southern United States. Hyperspectral remote sensing has shown promise as a tool for crop weed discrimination, and there is a growing interest in using this technology for identifying weeds in cotton production systems. Information is lacking on differentiating Palmer amaranth from cotton with an okra leaf structure based on canopy hyperspectral reflectance properties. Two greenhouse studies were conducted to compare canopy hyperspectral reflectance profiles of Palmer amaranth to canopy hyperspectral reflectance profiles of okra and super-okra leaf cotton and to identify optimal regions of the electromagnetic spectrum for their discrimination. Ground-based hyperspectral measurements of the plant canopies were obtained with a spectroradiometer (400 $2350 \mathrm{~nm}$ range). Analysis of variance (ANOVA, $p \leq 0.05$ ), Dunnett's test ( $p \leq$ 0.05 ), and difference and sensitivity measurements were tabulated to determine the optimal wavebands for Palmer amaranth and cotton discrimination. Results were inconsistent for Palmer amaranth and okra leaf cotton separation. Optimal wavebands for distinguishing Palmer amaranth from super-okra leaf cotton were observed in the shortwave infrared region $(2000 \mathrm{~nm}$ and $2180 \mathrm{~nm}$ ) of the optical spectrum. Ground-based and airborne sensors can be tuned into the shortwave infrared bands identified in this study, facilitating application of remote sensing technology for Palmer amaranth discrimination from super-okra leaf cotton and implementation of the technology as a decision support tool in cotton weed management programs.
\end{abstract}

\section{Keywords}

Amaranthus palmeri, Discrimination, Gossypium hirsutum, 


\section{Introduction}

Cotton (Gossypium spp.) is an important crop grown throughout the world. It is an important source of fiber and is one of the few crops with unique leaf shapes: 1) normal, 2) sub-okra, 3) okra, and 4) super-okra. Leaf shape plays a major role in cotton survival [1]. In cotton production systems, advantages and disadvantages have been documented for sub-okra, okra, and super-okra versus normal leaf cotton. A detailed review is provided in [1] and the references therein the differences between normal leaf versus sub-okra, okra, and super-okra leaf cotton types. Below is a summary of those differences.

Normal leaf cotton retains fewer bolls and produces yields that are equivalent to or slightly less than sub-okra leaf cotton (0 to less than $5 \%$ ). In comparison to normal leaf cotton, okra-leaf cotton has better chemical spray penetration $(+26 \%)$, less boll rot $(-44 \%)$, and more flowering $(+38 \%)$ and produces yields ranging from $8 \%$ less than to $20 \%$ greater than normal leaf cotton. Okra-leaf cotton produces less lint trash (15\%), has lower boll retention (-13\%), and reaches maturity approximately 6.5 days earlier than normal leaf cotton. Super-okra leaf cotton boll retention is $21 \%$ less than normal leaf cotton, and it has $20 \%$ less lint trash, produces $93 \%$ more flowers, and matures approximately ten days earlier, and has produced yields equivalent to or slightly less than $(0 \%$ to $-8 \%)$ normal leaf cotton. Research findings are inconsistent for the effect of cotton leaf type on disease and insect resistance.

Palmer amaranth is a major weed affecting cotton production systems in the southern U.S. [2] [3] [4]. In ideal environmental conditions, it grows faster and outcompetes cotton plants for available resources [5], and it has been linked to a reduction in cotton yield [3] [5] [6] [7]. Palmer amaranth is a prolific producer of seeds [2] [3] [8]; therefore, if allowed to mature, it establishes a seed bank that will affect next year's crop. Additionally, Palmer amaranth has developed resistance to several herbicides, mainly glyphosate; thus, making it difficult to control the aggressive weed [2] [9]. Chemical and mechanical methods are available for controlling Palmer amaranth [3] [10]. To better implement those strategies, producers need tools to help them identify or differentiate Palmer amaranth from cotton plants. There is a growing interest in using remote sensing technology for identifying weeds in cotton production systems.

Multispectral and hyperspectral light reflectance properties of plant leaves and canopies have shown promise for identifying optimal wavebands for crop weed discrimination [11]. Successes have been observed in spring wheat (Triticum aestivum L.) and canola (Brassica napus L.) [12], soybean (Glycine max L.) [13], and sunflower (Helianthus annuus L.) [14]. Reference [15], using hyperspectral data, identified optimal wavebands for separating cotton with different leaf colors from Palmer amaranth and redroot pigweed (Amaranthus retroflexus L.). 
Their study focused on leaf and not canopy reflectance measurements. Currently, there is no research available comparing the canopy hyperspectral profiles of okra and super-okra leaf cotton to the canopy hyperspectral profile of Palmer amaranth. Also, no information is available on which regions of the spectrum are optimal for okra and super-okra leaf canopies separation from Palmer amaranth.

The objectives of this study were to compare canopy hyperspectral reflectance properties of Palmer amaranth to canopy hyperspectral reflectance properties of okra and super-okra leaf cotton and to determine optimal regions of the optical spectrum for differentiating Palmer amaranth from okra and super-okra leaf cotton.

\section{Materials and Methods}

\subsection{Experimental Setup}

The research study was conducted at the United States Department of Agriculture, Agricultural Research Service, in Stoneville, MS (Latitude: 33.425168 Longitude: $-90.911875^{\circ}$ ). Palmer amaranth and okra and super-okra leaf cotton plants were grown in a greenhouse. Plant seeds were obtained from seed stock provided by scientists at the research facility. The Palmer amaranth used in the study was not resistant to herbicides. Two separate experiments were conducted. On December 12, 2017, and June 5, 2018, seeds of each plant were sown into seed trays containing commercial potting mix (Pro-Mix BX General Purpose Potting Mix, Premier Tech Horticulture, Rivière-du-Loup, QC, Canada). Approximately, ten days after emergence, seedlings were transplanted into 2-liter pots (Belden Jumbo Senior Square Pot, Greenhouse Mega Store, Danville, IL) containing commercial potting mix (Pro-Mix BX General Purpose Potting Mix).

The experimental design was a randomized complete block design consisting of 12 replications and three treatments (i.e., okra leaf cotton, super-okra leaf cotton, and Palmer amaranth). Plants were subjected to 14-hour daylength; greenhouse lighting was used to supplement ambient lighting conditions in the early morning (6:00 am - 8:00 am) and the late evening (6:00 pm - 8:00 pm). Plants were watered and fertilized (Dyna-Gro 777, Richmond, CA) as needed. The temperature in the greenhouse was maintained between $21.1^{\circ} \mathrm{C}$ and $32.2^{\circ} \mathrm{C}$.

\subsection{Data Collection}

Canopy reflectance measurements were obtained with the FieldSpec3 (Malvern Panalytical/Analytical Spectral Devices, Boulder, CO) full range hyperspectral spectroradiometer. They were acquired on January 15, 2018, and July 13, 2018, for the first and the second experiments, respectively. Reflectance measurements were acquired $30 \mathrm{~cm}$ above the plant canopy, resulting in the instrument viewing an area of $139 \mathrm{~cm}^{2}$. The plants were moved from the greenhouse to outside to obtain the spectral measurements. These measurements were obtained on sunny days \pm 2 hours of solar noon. For both experiments, Palmer amaranth plant 
growth stage ranged from vegetative to inflorescence; whereas, the cotton plants growth stage ranged from vegetative to squaring. The goals were to obtain the canopy reflectance measurements during the vegetative growth stage and when the okra and super okra leaf canopies had developed characteristic leaf structure for its type. However, weather conditions hindered us from collecting the spectrum during that time. Thus, data were collected as close as possible to the desired growth stage, the vegetative stage. Furthermore, Palmer amaranth plants grow much faster than the cotton plants resulting in them being further along in their growth.

Before collecting the spectral measurements, black felt cloth was used to obscure the potting mix background, and it was used as the background surface for placing the pots. The black felt reflectance was approximately $3 \%$ in the visible to shortwave infrared regions of the spectrum. At 15-minute intervals, the spectroradiometer was calibrated using a white spectralon panel (white reference). Reflectance data obtained for each plant was an average of 15 readings.

The FieldSpec 3 spectroradiometer measures light reflectance in the $350 \mathrm{~nm}$ to $2500 \mathrm{~nm}$ spectral range. Its spectral resolutions are $3 \mathrm{~nm}$ at $700 \mathrm{~nm}$ and $10 \mathrm{~nm}$ at $1400 \mathrm{~nm}$ and $2100 \mathrm{~nm}$. The sampling intervals of the instrument are $1.4 \mathrm{~nm}$ for the $350-1050 \mathrm{~nm}$ range and $2 \mathrm{~nm}$ for the $1000-2500 \mathrm{~nm}$ range. The software used to operate the instrument interpolates the final spectrum to $1 \mathrm{~nm}$ along the $350 \mathrm{~nm}$ to $2500 \mathrm{~nm}$ range.

\subsection{Data Processing}

The FieldSpec 3 spectroradiometer has three built-in sensors: 1) one silicon photodiode array and 2) two separate indium gallium arsenide photodiodes. At the change point from one sensor to the other, a step occurs in the data. Steps were eliminated at 1000 and $1800 \mathrm{~nm}$ with the splice correction function [16] [17] of the ViewSpec Pro software (Version 6.2, Malvern Panalytical/Analytical Spectral Devices, Boulder, CO.).

The data were smoothed with the Savitzky-Golay [18] filter ( $\mathrm{n}=25$ points to use for smoothing the data) and were aggregated to $10 \mathrm{~nm}$ wavebands. The filter and the selected bandwidths preserved features of the spectral data such as relative maxima, minima, and widths. Wavebands that are not commonly used for remote sensing of vegetation (i.e., reflectance values below $400 \mathrm{~nm}$ ), that occur in strong atmospheric water absorption regions $(1360 \mathrm{~nm}-1450 \mathrm{~nm}$ and $1800 \mathrm{~nm}-$ $1990 \mathrm{~nm}$ ), and that represented noisy spectra were removed (i.e., wavebands above $2350 \mathrm{~nm}$ ). Data processing was completed with HSDAR package [19] of R software (Version 3.4.3, "Kite-Eating Tree," [20]).

\subsection{Data Analyses}

Data were analyzed with analysis of variance (ANOVA, $p \leq 0.05$, [21] [22]), Dunnett's test ( $p \leq 0.05,[23])$, difference analysis, and sensitivity analysis [24]. ANOVA provided general information on regions of the spectrum where differences existed among groups. Dunnett's test was used to determine statistically 
significant differences between Palmer amaranth and a specific cotton group spectrum. It was tabulated only in regions of the spectrum in which the ANOVA indicated statistically significant $(p \leq 0.05)$ differences among groups. Reflectance difference was tabulated by subtracting the mean Palmer amaranth spectrum from the mean spectrum for a specific cotton group. Reflectance sensitivity was determined by dividing the mean difference of Palmer amaranth and a cotton group by the mean of the Palmer amaranth spectrum. It was used to determine the optimal wavebands for Palmer amaranth and cotton discrimination. Reflectance sensitivity values are positive or negative. The closer the value is to zero on the positive or negative scale, the lower is its ranking. Statistical analysis was completed with the R software [20].

\section{Results}

\subsection{Qualitative Assessment of Hyperspectral Reflectance Curves}

The mean hyperspectral reflectance curves of Palmer amaranth, okra leaf cotton, and super-okra leaf cotton canopies are illustrated in Figure 1(a) and Figure 2(a). The curves were similar in pattern and were representative of the typical spectral curve for healthy vegetation in that healthy vegetation minimum reflectance occurs in the visible region of the spectrum with a notable increase in the green region of the visible spectrum (500-600 nm); a sharp increase in reflectance arises from $600-800 \mathrm{~nm}$ and plateaus at $900 \mathrm{~nm}$ in the near infrared region of the spectrum; and then the reflectance decreases in the shortwave infrared region of the spectrum.

Differences were observed in the amplitudes of the plant spectral curves in the visible, near infrared, red edge, and shortwave infrared regions of the spectrum. Generally, Palmer amaranth canopy hyperspectral reflectance values were lower than the okra leaf cotton canopy hyperspectral reflectance values in the near infrared region of the spectrum. In the shortwave infrared region of the spectrum, Palmer amaranth canopy hyperspectral response was greater than super-okra leaf cotton canopy hyperspectral response.

\subsection{Data Analyses}

For experiments one and two, statistically significant differences $(p \leq 0.05)$ in reflectance values of the plant groups were observed for $69(1460-1790 \mathrm{~nm}$ and $2010-2350 \mathrm{~nm}$ ) and 166 wavebands (400 - $1350 \mathrm{~nm}, 1460-1790 \mathrm{~nm}$, and 2000 $2350 \mathrm{~nm}$ ), respectively (Figure 1(a) and Figure 2(a)). Dunnett's test indicated for the first experiment that statistically significant differences occurred for Palmer amaranth and super-okra leaf cotton for all 69 bands identified by the ANOVA (Figure 1(b), $1460-1790 \mathrm{~nm}$ and $2010-2350 \mathrm{~nm}$ ); in contrast, no statistically significant differences were observed between Palmer amaranth and okra leaf cotton reflectance values.

For the second experiment, Dunnett's test showed that the differences in reflectance values were statistically significant $(p \leq 0.05)$ between Palmer amaranth 


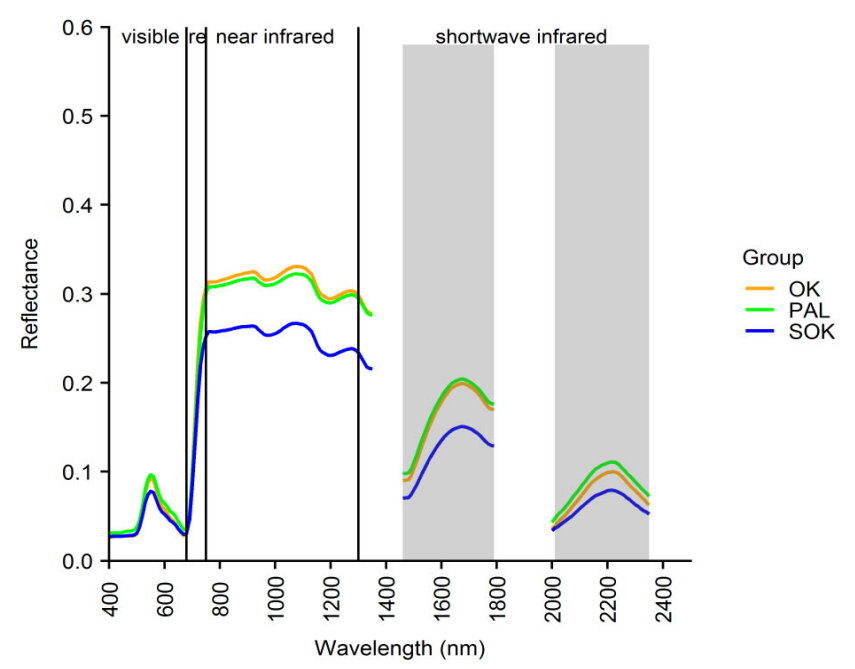

(a)

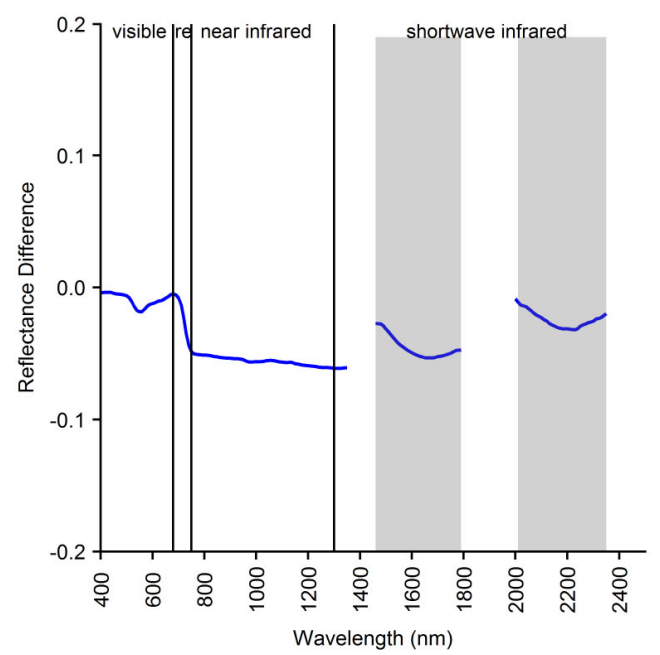

(b)

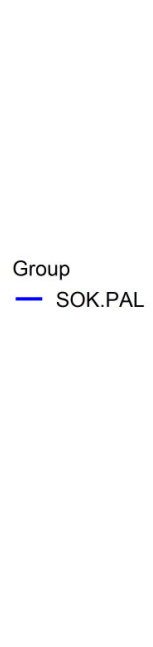

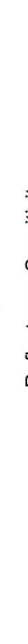

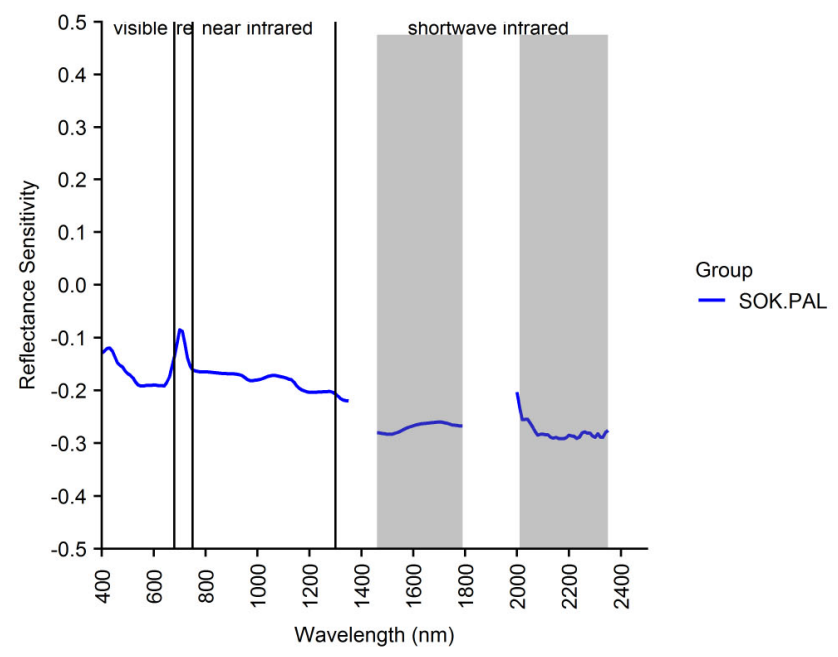

(c)

Figure 1. (a) Mean ( $\mathrm{n}=12$ ) canopy reflectance of Palmer amaranth (PAL), okra leaf cotton (OK), and super-okra leaf cotton (SOK), January 15, 2018. Reflectance difference of (b) PAL versus SOK leaf cotton. Gray shaded areas in (a) indicate a statistically significant difference in reflectance between groups as determined with ANOVA $(p \leq 0.05)$. Gray shaded areas in (b) represent statistically significant difference between PAL and SOK leaf cotton as determined with Dunnett's test $(p \leq 0.05)$. Reflectance sensitivity of (c) PAL versus SOK leaf cotton in Dunnett's test statistically significant zones.

and okraleaf cotton for 107 wavebands $(400-490 \mathrm{~nm}, 520-640 \mathrm{~nm}, 670 \mathrm{~nm}$, $690-1350 \mathrm{~nm}, 2000-2100 \mathrm{~nm}, 2310-2350 \mathrm{~nm}$ ) and between Palmer amaranth and super-okra leaf cotton for 62 wavebands (400 - $510 \mathrm{~nm}, 650$ - $680 \mathrm{~nm}, 1460$ $1540 \mathrm{~nm}, 1790-2350 \mathrm{~nm}$ ). According to the sensitivity analysis, the optimal waveband for Palmer amaranth and okra leaf cotton differentiation on the second date was at $710 \mathrm{~nm}$ (sensitivity $=0.59$ ), the red-edge region of the spectrum (Figure 2(d)). For Palmer amaranth and super-okra leaf cotton, sensitivity analysis indicated that the optimal wavebands occurred in the shortwave infrared region of the spectrum at $2180 \mathrm{~nm}$ (sensitivity $=-0.29$ ) and $2000 \mathrm{~nm}$ (sensitivity $=0.42$ ) for the first and second experiment, respectively (Figure $1(\mathrm{c})$ and Figure 2(e)). 


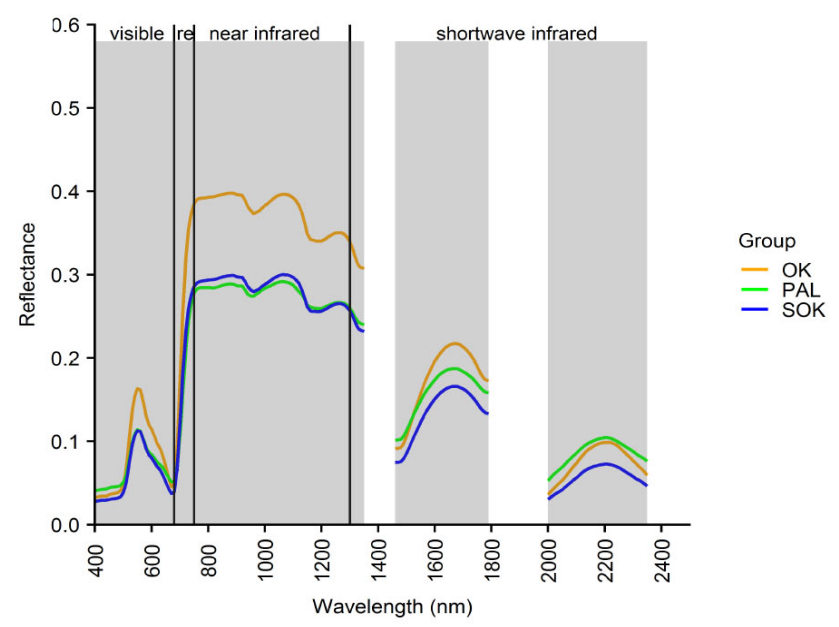

(a)

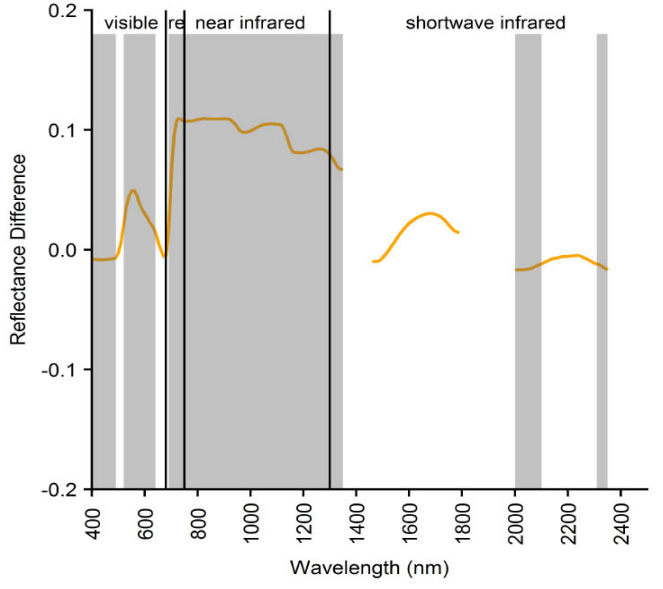

(b)

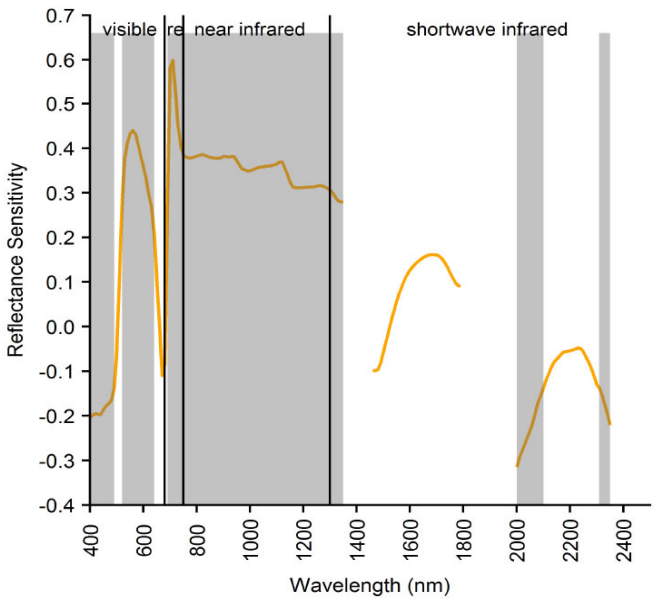

(d)

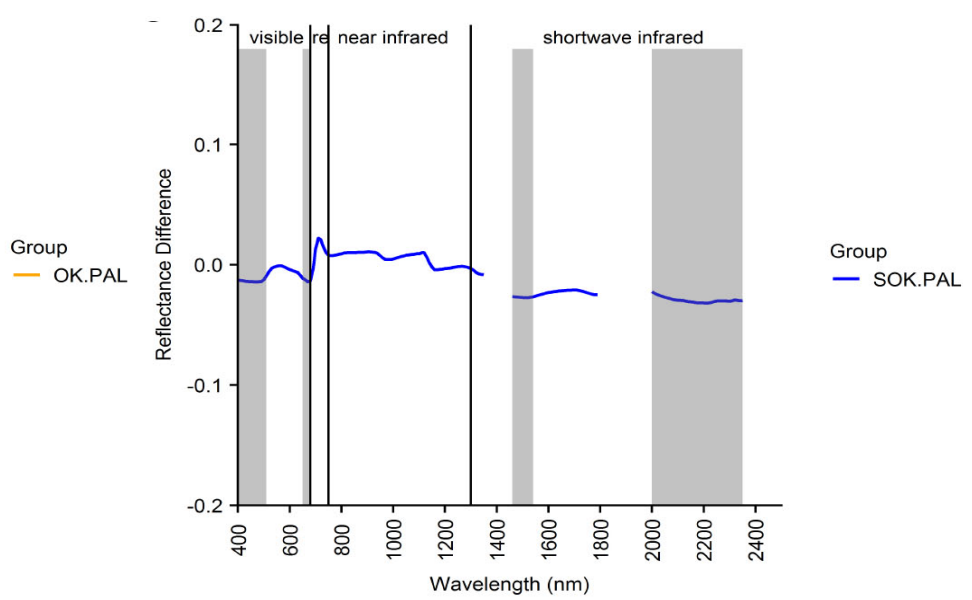

(c)
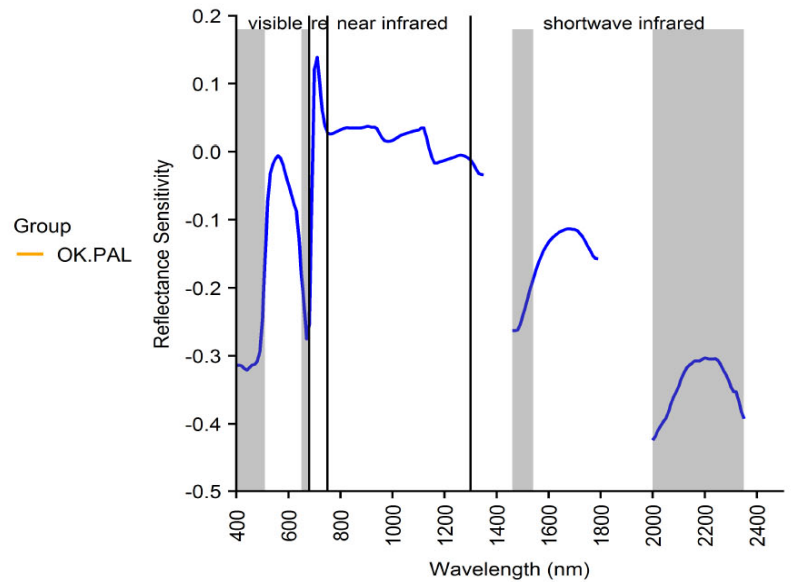

(e)

Figure 2. (a) Mean ( $\mathrm{n}=12$ ) canopy reflectance of Palmer amaranth (PAL), okra leaf cotton (OK), and super-okra leaf cotton (SOK), July 13, 2018. Reflectance difference of (b) PAL versus OK leaf cotton and (c) PAL versus SOK leaf cotton. Gray shaded areas in (a) indicate a statistically significant difference in reflectance between the groups as determined with ANOVA ( $p \leq 0.05$ ). Gray shaded areas in (b) and (c) illustrate statistically significant difference between PAL versus OK leaf cotton and PAL versus SOK leaf cotton, respectively, as determined with Dunnett's test $(p \leq 0.05)$. Reflectance sensitivity of (d) PAL versus OK leaf cotton and (e) PAL versus SOK leaf cotton in Dunnett's test statistically significant zones. 


\section{Discussion}

Inconsistencies were observed in the spectral reflectance properties of Palmer amaranth versus okra leaf cotton; noticeable differences were observed in the near infrared region of the spectrum between the two plant canopies for the second experiment compared to the first experiment. Data from the first experiment indicated the near infrared reflectance properties of Palmer amaranth canopies were like the near infrared reflectance properties of okra leaf canopies, and on the second date, Palmer amaranth near infrared canopy reflectance was like super-okra leaf canopy reflectance. Near infrared light is highly reflected at the air-cell water interphase of the spongy mesophyll tissue of plant leaves [25] [26] [27]. At the canopy level, leaf area, plant biomass, in-canopy shadowing, and leaf angle contribute to the level of near infrared light reflected by the plant [28].

For the first experiment, the leaves in the Palmer amaranth canopy were close together and overlapping. For the second experiment, the Palmer amaranth canopy structure was more open, meaning that more open spaces were apparent between the leaves. Furthermore, the Palmer amaranth plants measured in the second experiment were more mature than the Palmer amaranth plants measured in the first experiment. Variations in leaf area, plant biomass, in-canopy shadowing, and leaf angle contributed to the non-significant and statistically significant differences observed between Palmer amaranth and okra leaf cotton for the first and second dates, respectively.

Based on the sensitivity analysis, wavebands in the shortwave infrared region of the spectrum were deemed optimal for differentiating Palmer amaranth and super-okra leaf cotton (Figure 1 and Figure 2). The shortwave infrared region of the spectrum is sensitive to the water content in plant leaves [27] [28] [29] and is also affected by in-canopy shadowing, background, canopy architecture, and leaf area. Researchers have confirmed that super-okra leaf cotton leaves were $52 \%$ the size of normal cotton leaves and that super-okra leaf cotton leaves are significantly smaller than okra leaves [1] [30] [31] [32]. Also, it was observed that super-okra leaf cotton had more background showing through its canopy compared with Palmer amaranth and okra-leaf cotton when observed at a nadir position above the canopy. Therefore, we believe that the canopy architecture and background affected the differences observed between Palmer amaranth and super-okra leaf cotton in the shortwave infrared regions of the spectrum.

Reflectance bands occurring in the same region of the spectrum are usually highly correlated; thus, any waveband appearing in the statistically significant zone of the Dunnett's test in the shortwave infrared region of the spectrum would suffice for Palmer amaranth and super-okra leaf cotton discrimination. Therefore, it is believed that a frame based hyperspectral camera sensitive to the shortwave infrared region of the would have good potential for discriminating Palmer amaranth from super-okra leaf cotton. 


\section{Conclusion}

Hyperspectral data can serve as a valuable tool for developing spectral libraries for Palmer amaranth and cotton, leading to the identification of spectral bands to use on sensors for Palmer amaranth and cotton discrimination. For this study, shortwave infrared bands were optimal for Palmer amaranth and super-okra leaf cotton differentiation. Commercially available sensors can be tuned to the optimal bands identified in this study, facilitating application of remote sensing technology for Palmer amaranth discrimination from super-okra leaf cotton and implementation of the technology as a decision support tool in weed management programs. Results of the two experiments were inconsistent for Palmer amaranth and okra leaf cotton separation. Therefore, our future research initiatives will focus on testing vegetation indices and derivative spectra as tools for discriminating Palmer amaranth and okra leaf cotton.

\section{Acknowledgements}

The authors would like to thank Milton Gaston Jr., Destraile Jackson, MekaelaBrisco, and Zhaquavez Petty for their assistance in this study. Mention of a trade name, proprietary product, or specific equipment does not constitute a guarantee or warranty by the United States Department of Agriculture and does not apply endorsement of a product to the exclusion of others that may be suitable.

\section{Conflicts of Interest}

The authors declare no conflicts of interest regarding the publication of this paper.

\section{References}

[1] Andres, R.J., Bowman, D.T., Jones, D.C. and Kuraparthy, V. (2016) Major Leaf Shapes of Cotton: Genetics and Agronomic Effects in Crop Production. The Journal of Cotton Science, 20, 330-340.

[2] Nichols, R.L., Bond, J., Culpepper, A.S., Dodds, D., Nandula, V., Main, C.L., et al. (2009) Glyphosate-Resistant Palmer amaranth (Amaranthus palmeri) Spreads in the Southern United States (U.S.). Resistant Pest Management Newsletter, 18, 8-10.

[3] Ward, S.M., Webster, T.M. and Steckel, L.E. (2013) Palmer amaranth (Amaranthus palmeri): A Review. Weed Technology, 27, 12-27. https://doi.org/10.1614/WT-D-12-00113.1

[4] Webster, T.M. and Nichols, R.L. (2012) Changes in the Prevalence of Weed Species in the Major Agronomic Crops of the Southern United States: 1994/1995 to 2008/2009. Weed Science, 60, 145-157. https://doi.org/10.1614/WS-D-11-00092.1

[5] Morgan, G.D., Baumann, P.A. and Chandler, J.M. (2001) Competitive Impact of Palmer Amaranth (Amaranthus palmeri) on Cotton (Gossypium hirsutum) Development and Yield. Weed Technology, 15, 408-412. https://doi.org/10.1614/0890-037X(2001)015[0408:CIOPAA]2.0.CO;2

[6] Rowland, M.W., Murray, D.S. and Verhalen, L.M. (1999) Full-Season Palmer amaranth (Amaranthus palmeri) Interference with Cotton (Gossypium hirsutum). Weed Science, 47, 305-309. 
[7] MacRae, A.W., Culpepper, A.S., Webster, T.M., Sosnoskie, L.M. and Kichler, J.M. (2008) Glyphosate-Resistant Palmer amaranth Competition with Roundup Ready Cotton. Proceedings of the 2008 Beltwide Cotton Conference, Nashville, 8-11 January 2008, 1696.

[8] Keeley, P.E., Carter, C.H. and Thullen, R.J. (1987) Influence of Planting Date on Growth of Palmer amaranth (Amaranthus palmeri). Weed Science, 35, 199-204.

[9] Salas, R.A., Burgos, N.R., Tranel, P.J., Singh, S., Glasgow, L., Scoot, R.C., et al. (2016) Resistance to PPO-Inhibiting Herbicide in Palmer amaranth from Arkansas. Pest Management Science, 72, 864-869. https://doi.org/10.1002/ps.4241

[10] Lindsay, K., Popp, M., Norsworthy, J., Bagavathiannan, M., Powles, S. and Lacoste, M. (2017) PAM: Decision Support for Long-Term Palmer amaranth (Amaranthus palmeri) Control. Weed Technology, 31, 915-927.

https://doi.org/10.1017/wet.2017.69

[11] Thorp, K. and Tian, L. (2004) A Review on Remote Sensing of Weeds in Agriculture. Precision Agriculture, 5, 477-508. https://doi.org/10.1007/s11119-004-5321-1

[12] Smith, A.M. and Blackshaw, R.E. (2003) Weed-Crop Discrimination Using Remote Sensing:a Detached Leaf Experiment. Weed Technology, 17, 811-820.

https://doi.org/10.1614/WT02-179

[13] Koger, C.H., Shaw, D.R., Reddy, K.N. and Bruce, L.M. (2004) Detection of Pitted Morningglory (Ipomoea lacunosa) with Hyperspectral Remote Sensing. II. Effects of Vegetation Ground Cover and Reflectance Properties. Weed Science, 52, 230-235. https://doi.org/10.1614/WS-03-083R1

[14] Peña-Barragãn, J.M., López-Granados, F., Jurado-Expósito, M. and Garciá-Torres, L. (2006) Spectral Discrimination of Ridolfia segetum and Sunflower as Affected by Phenological Stage. Weed Research, 46, 10-21. https://doi.org/10.1111/j.1365-3180.2006.00488.x

[15] Fletcher, R.S., Reddy, K.N. and Turley, R.B. (2016) Spectral Discrimination of Two Pigweeds from Cotton with Different Leaf Colors. American Journal of Plant Sciences, 7, 2138-2150. https://doi.org/10.4236/ajps.2016.715190

[16] Garfagnoli, F., Ciampalini, A., Moretti, S., Chiarantini, L. and Vettori, S. (2013) Quantitative Mapping of Clay Minerals Using Airborne Imaging Spectroscopy: New Data on Mugello (Italy) from SIM-GA Prototypal Sensor. European Journal of Remote Sensing, 46, 1-17. https://doi.org/10.5721/EuJRS20134601

[17] Danner, M., Locherer, M., Hank, T. and Richter, K. (2015) Spectral Sampling with the ASD FieldSpec 4 Theory, Measurement, Problems, Interpretation. EnMAP Field Guides Technical Report, GFZ Data Services.

[18] Savitzky, A. and Golay, M.J.E. (1964) Smoothing and Differentiation of Data by Simplified Least Squares Procedures. Analytical Chemistry, 36, 1627-1639. https://doi.org/10.1021/ac60214a047

[19] Lehnert, L.W., Meyer, H. and Bendix, J. (2018) HSDAR: Manage, Analyze, and Simulate Hyperspectral Data in R. R Package Version 0.7.1.

[20] R Core Team (2017) R: A Language and Environment for Statistical Computing. R Foundation for Statistical Computing, Vienna. https://www.R-project.org/

[21] Steele, R.G.D. and Torrie, J.H. (1960) Principles and Procedures of Statistics. McGraw-Hill, New York.

[22] Clewer, A.G. and Scarisbrick, D.H. (2001) Practical Statistics and Experimental Design for Plant and Crop Science. John Wiley and Sons, New York.

[23] McHugh, M.L. (2011) Multiple Comparison Analysis Testing in ANOVA. Bioche- 
mia Medica, 21, 203-209. https://doi.org/10.11613/BM.2011.029

[24] Carter, G.A., Dell, T.R. and Cibula, W.G. (1996) Spectral Reflectance Characteristics and Digital Imagery of a Pine Needle Blight in the Southeastern United States. Canadian Journal of Forestry Research, 26, 402-407. https://doi.org/10.1139/x26-045

[25] Jensen, J.R. (2000) Remote Sensing of the Environment: An Earth Resource Perspective. 2nd Edition, Prentice-Hall, Upper Saddle River.

[26] Campbell, J.B. (2000) Introduction to Remote Sensing. 3rd Edition, The Guilford Press, New York.

[27] Sahoo, R.N., Ray, S.S. and Manjunath, K.R. (2015) Hyperspectral Remote Sensing of Agriculture. Current Science, 108, 848-859.

[28] Thenkabail, P.S., Gumma, M.K., Teluguntla, P. and Mohammed, I.A. (2014) Hyperspectral Remote Sensing of Vegetation and Agricultural Crops. Photogrammetric Engineering and Remote Sensing, 80, 697-709.

[29] Govender, M., Dye, P.J., Weiersbye, I.M., Witkowski, E.T.F. and Ahmed, F. (2009) Review of Commonly Used Remote Sensing and Ground-Based Technologies to Measure Plant Water Stress. Water SA, 35, 741-752. https://doi.org/10.4314/wsa.v35i5.49201

[30] Andries, J.A., Jones, J.E., Sloane, L.W. and Marshall, J.G. (1969) Effects of Okra Leaf Shape on Boll Rot, Yield, and Other Important Characters of Upland Cotton, Gossypium hirsutum L. Crop Science, 9, 705-710. https://doi.org/10.2135/cropsci1969.0011183X000900060009x

[31] Wells, R., Meredith, W.R. and Williford, J.R. (1986) Canopy Photosynthesis and Its Relationship to Plant Productivityin Near-Isogenic Cotton Lines Differing in Leaf Morphology. Plant Physiology, 82, 635-640. https://doi.org/10.1104/pp.82.3.635

[32] Zhu, W., Liu, K. and Wang, X.D. (2008) Heterosis in Yield, Fiber Quality, and Photosynthesis of Okra Leaf Oriented Hybrid Cotton (Gossypium hirsutum L.). Euphytica, 164, 283-291. https://doi.org/10.1007/s10681-008-9732-3 